\title{
Monitoring Antibiotic Residues and Corresponding Antibiotic Resistance Genes in an Agroecosystem
}

\author{
Yasser M. Awad, ${ }^{1}$ Kwon Rae Kim, ${ }^{2}$ Sung-Chul Kim, ${ }^{3}$ Kangjoo Kim, \\ Sang Ryong Lee, ${ }^{5}$ Sang Soo Lee, ${ }^{1}$ and Yong Sik $\mathrm{Ok}^{1}$ \\ ${ }^{1}$ Department of Biological Environment, Kangwon National University, Chuncheon 200-701, Republic of Korea \\ ${ }^{2}$ Department of Agronomy, Oriental Medicine Resource, Gyeongnam National University of Science and Technology, \\ Jinju 660-758, Republic of Korea \\ ${ }^{3}$ Department of Bio-Environmental Chemistry, Chungnam National University, Daejeon 305-764, Republic of Korea \\ ${ }^{4}$ Department of Environmental Engineering, Kunsan National University, Kunsan 573-701, Republic of Korea \\ ${ }^{5}$ Department of Animal Biotechnology and Environment, National Institute of Animal Science, Rural Development Administration, \\ Suwon 441-706, Republic of Korea \\ Correspondence should be addressed to Sang Soo Lee; sslee97@kangwon.ac.kr and Yong Sik Ok; soilok@kangwon.ac.kr
}

Received 16 December 2014; Revised 13 February 2015; Accepted 22 February 2015

Academic Editor: Athanasios Katsoyiannis

Copyright (C) 2015 Yasser M. Awad et al. This is an open access article distributed under the Creative Commons Attribution License, which permits unrestricted use, distribution, and reproduction in any medium, provided the original work is properly cited.

\begin{abstract}
Antibiotic resistance genes (ARGs) have been commonly reported due to the overuse worldwide of antibiotics. Antibiotic overuse disturbs the environment and threatens public human health. The objective of this study was to measure the residual concentrations of veterinary antibiotics in the tetracycline group (TCs), including tetracycline (TC) and chlortetracycline (CTC), as well as those in the sulfonamide group (SAs), including sulfamethazine (SMT), sulfamethoxazole (SMX), and sulfathiazole (STZ). We also isolated the corresponding ARGs in the agroecosystem. Four sediment samples and two rice paddy soil samples were collected from sites near a swine composting facility along the Naerincheon River in Hongcheon, Korea. High performance liquid chromatographytandem mass spectrometry (HPLC-MS/MS) was employed with a solid-phase extraction method to measure the concentration of each antibiotic. ARGs were identified by the qualitative polymerase chain-reaction using synthetic primers. SAs and their corresponding ARGs were highly detected in sediment samples whereas TCs were not detected except for sediments sample \#1. ARGs for TCs and SAs were detected in rice paddy soils, while ARGs for TCs were only found in sediment \#2 and \#4. Continuous monitoring of antibiotic residue and its comprehensive impact on the environment is needed to ensure environmental health.
\end{abstract}

\section{Introduction}

Veterinary antibiotics are generally used as additives to maintain animal health and to promote animal growth. In the USA, approximately 12,500 tons of antibiotics is used for livestock production every year $[1,2]$. A large amount of antibiotics in the form of active pharmaceutical ingredients has been used in animal husbandry and on fish farms because of their high efficiency to promote growth or control disease [3]. However, $>80 \%$ of the antibiotics used are excreted as active metabolites in feces and urine [2]. Subsequently, the excreted antibiotic residues are delivered to the surrounding environment, resulting in elevating antibiotic concentrations [4-6]. The antibiotic residues of four antibiotic groups including tetracyclines (TCs), sulfonamides (SAs), macrolides (MLs), and ionophores are detectable in water and sediment near the mixed-landscape of the Cache La Poudre River watershed [7]. The occurrence of antibiotic residues along a water system is more critical because they are highly mobile [7].

Release of antibiotics into the environment leads to the strains of pathogenic antibiotic-resistant bacteria [8-11]. For example, TC resistance genes have been reported in water samples collected from wastewater treatment plants near swine production facilities in the USA $[8,10]$. Sengeløv et al. [12] also detected antibiotic resistance genes (ARGs) against TC, MLs, and streptomycin in bacteria isolated from five farmlands treated with swine manure slurry. Rysz and 
TABle 1: Description of each sediment and soil sample.

\begin{tabular}{ll}
\hline Site & Site description \\
\hline Sediment \#1 & Site located $0.2 \mathrm{~km}$ away from a swine manure compositing facility \\
Sediment \#2 & Site located $0.5 \mathrm{~km}$ away from a swine manure compositing facility \\
Sediment \#3 & Site located $1.0 \mathrm{~km}$ away from a swine manure compositing facility \\
Sediment \#4 & $\begin{array}{l}\text { Site located } 1.5 \mathrm{~km} \text { away from a swine manure compositing facility } \\
\text { Soil \#1 }\end{array}$ \\
$\begin{array}{l}\text { Rice paddy soil treated with swine manure and having a distance of } 2.0 \mathrm{~km} \text { from a swine manure composting facility } \\
\text { Soil \#2 }\end{array}$ & $\begin{array}{l}\text { Rice paddy soil influencing antibiotics via irrigation and having a distance of } 2.0 \mathrm{~km} \text { from a swine manure } \\
\text { composting facility }\end{array}$ \\
\hline
\end{tabular}

Alvarez [13] insisted that dissemination of ARGs severely degrades environments biochemically and should be considered a pollutant.

Once antibiotic residues enter bacterial cells in the environment via passive diffusion, they inhibit bacterial growth [14]. TCs, including TC, chlortetracycline (CTC), oxytetracycline (OTC), doxycycline (DXC), and minocycline (MNC) inhibit protein synthesis in Gram-positive and Gramnegative bacteria by preventing the binding of aminoacyltRNA molecules to the $30 \mathrm{~S}$ ribosomal subunit [14]. Bacterial resistance to these antibiotics occurs by two mechanisms: (i) the multiantibiotic-resistance pump and (ii) conferring of bacterial resistance $[14,15]$.

Antibiotic research related to resistance genes has been confined to culturable bacteria isolated from pharmaceutically originating wastewater. The cultural isolation method is the most commonly employed; however, only a fraction of actual microbiota in systems containing ARGs can be determined using this method [16]. According to ARG occurrence in environments affected by animal waste, the polymerase chain-reaction (PCR) method is highlighted to quantify genes conferring resistance to selective antibiotics. Several studies have attempted to quantify ARGs by isolating DNA [11, 17]. Knapp et al. [18] showed that isolated DNA from five long-term soil series (over 60 years) was very informative regarding ARG abundance and their resistance to antibiotics. They also found that ARGs have increased sharply in the environment from 1940 to 2008. Differently designed primers are needed to detect antibiotic bacterial resistance. Bacterial resistance to different types of antibiotics was primarily mediated by synthetic primers, such as tet(A)$(\mathrm{E}), \operatorname{tet}(\mathrm{G}), \operatorname{tet}(\mathrm{M}), \operatorname{tet}(\mathrm{O}), \operatorname{tet}(\mathrm{Q})$, and $\operatorname{tet}(\mathrm{S})$, for TCs $[11,19]$ and $\operatorname{sul}(\mathrm{I})$ and $\operatorname{sul}(\mathrm{II})$ for SAs [5].

To understand the relationship between antibiotics and corresponding ARGs, seasonal monitoring of veterinary antibiotics is needed due to the variation of climatic features in Korea and the overused annual consumption of antibiotics compared to other countries [20]. Korea has high-intensity rainfall and a large temperature difference between summer and winter seasons due to the geographical monsoon impact [21]. This climate condition can lead to the mobilization of antibiotics, owing to the contamination of surrounding environment. A continuous monitoring of antibiotics has been performed near concentrated animal farming operations (CAFOs) in Korea and antibiotics were detected in environment as mentioned in our previous studies [20, 22].
This study was conducted to further evaluate the presence of veterinary antibiotic residues released into the environment and to identify ARGs in environmental components such as sediment and soil possibly affected by a swine manure-based compost facility.

\section{Materials and Methods}

2.1. Sampling. The sampling sites were located in Hongcheon, Gangwon Province, Korea, which were assumed to be affected by antibiotic release from a swine manure composting facility $\left(37^{\circ} 34^{\prime} 28^{\prime \prime} \mathrm{N}, 127^{\circ} 52^{\prime} 26^{\prime \prime} \mathrm{E}\right)$. Specific descriptions of the sampling sites are provided in Table 1. Sampling was done in March 2009. The average temperature was $17.7^{\circ} \mathrm{C}$ and total precipitation was $95.8 \mathrm{~mm}$ [23]. Sediments were sampled based on the distance from the composting facility of $0.2,0.5,1$, and $1.5 \mathrm{~km}$ as sediment sample \#1, \#2, \#3, and \#4, respectively, along the Naerincheon River. Paddy soils were collected from sites (a) directly applied with swine manure for agricultural purposes as soil \#1 and (b) only irrigated using a water source from Naerincheon River as soil \#2. Specifically, sediment and soil samples were collected at a depth of $0-$ $20 \mathrm{~cm}$. Four subsamples were collected from each site and these subsamples formed a composite sample. The sediment and soil samples were air-dried and then passed through a 2-mm sieve before analysis. The current study is a part of a comprehensive monitoring (since April 2008) of antibiotics in water, sediment, and soil near swine composting facility $[20,22]$.

2.2. Antibiotic Extraction and Quantification. Antibiotic residues were extracted from the sediment and soil samples using the method described by Kim and Carlson [24] and Ok et al. [20] and were quantified by high performance liquid chromatography-tandem mass spectrometry (HPLCMS/MS) (API 3000, Applied Biosystems, Foster City, CA, USA). Recovery and the limit of quantification were determined. Briefly, to extract TCs and SAs, $1 \mathrm{~g}$ of sediment or soil sample was added to a $50 \mathrm{~mL}$ polypropylene centrifuge tube with $20 \mathrm{~mL}$ of McIlvaine buffer at $\mathrm{pH} 4$ buffer solution and $200 \mu \mathrm{L}$ of $5 \% \mathrm{Na}_{2}$ EDTA, followed by $20 \mathrm{~min}$ of shaking at $400 \mathrm{rpm}$ before centrifugation for $15 \mathrm{~min}$ at 4,000 rpm (Centrifuge FLETA 5, Hanil Science Industry, Seoul, Korea). The supernatant was filtered through a $0.2 \mu \mathrm{m}$ glass fiber filter. The extraction process was repeated, and the extracts were combined in a $40 \mathrm{~mL}$ vial for solid-phase 
TABLE 2: Conditions for high performance liquid chromatography-tandem mass (HPLC-MS/MS) spectrometry.

\begin{tabular}{|c|c|c|}
\hline Equipment & \multicolumn{2}{|c|}{ LC MS/MS (TSQ Quantum Ultra, Thermo) } \\
\hline \multirow{8}{*}{ LC condition } & Column temp. & $15^{\circ} \mathrm{C}$ \\
\hline & Column flow rate & $300 \mu \mathrm{L} \mathrm{min}^{-1}$ \\
\hline & Injection volume & $20 \mu \mathrm{L}$ \\
\hline & \multirow{2}{*}{ Mobile phase } & A: $99.9 \%$ water $+0.1 \%$ formic acid \\
\hline & & B: $99.9 \% \mathrm{ACN}+0.1 \%$ formic acid \\
\hline & \multirow{3}{*}{ Gradient } & A: $96 \%+B: 4 \%(0 \min )$ \\
\hline & & $\mathrm{A}: 70 \%+\mathrm{B}: 30 \%(29 \mathrm{~min})$ \\
\hline & & A: $96 \%+B: 4 \%(30 \min )$ \\
\hline \multirow{7}{*}{ MS condition } & Ion source & ESI, positive \\
\hline & Spray voltage & $4500 \mathrm{~V}$ \\
\hline & Vaporizer temp. & $320^{\circ} \mathrm{C}$ \\
\hline & Drying gas flow & $10.0 \mathrm{Lmin}^{-1}$ \\
\hline & Drying gas and nebulizer gas & Nitrogen gas \\
\hline & Sheath gas pressure & 40 psig \\
\hline & Aux gas pressure & 20 psig \\
\hline
\end{tabular}

extraction (SPE). SPE was employed to retain antibiotics on the cartridge so they could be effectively extracted with $\mathrm{MeOH}$ [25]. Due to the wide range in $\mathrm{pH}$, hydrophiliclipophilic balanced cartridges were used for the antibiotic extraction and preextractants were purified on solid matrices [25]. Electrospray ionization was also applied to quantify antibiotic substances using HPLC-MS/MS in positive mode. The detailed information and mobile phase conditions are summarized in Table 2.

\subsection{Heterotrophic Plate Counts on Antibiotic-Selective Media.}

Each $1 \mathrm{~g}$ of moist sediment/soil sample was diluted in sterilized water and agitated for $30 \mathrm{~min}$, followed by a 100fold serial dilution. Aliquots $(100 \mu \mathrm{L})$ of the serially diluted sample were spread directly onto the surface of R2A agar media (Difco, Sparks, MD, USA), which contained various antibiotics or no antibiotic as a control to enumerate and isolate resistant bacteria. Specifically, the media contained antibiotics of $30 \mathrm{mg} \mathrm{L}^{-1} \mathrm{TC}, 70.55 \mathrm{mg} \mathrm{L}^{-1} \mathrm{CTC}, 45.55 \mathrm{mg} \mathrm{L}^{-1}$ OTC, $281.8 \mathrm{mg} \mathrm{L}^{-1} \mathrm{SMT}, 50.4 \mathrm{mg} \mathrm{L}^{-1} \mathrm{SMX}$, or $45 \mathrm{mg} \mathrm{L}^{-1} \mathrm{STZ}$. A concentration that was five times greater than the reported average $\mathrm{LD}_{50}$ value was used for the water-soluble antibiotics such as TC, CTC, and STZ, whereas the maximum amount that dissolved readily in water when added to melted agar was used for the insoluble antibiotics such as SMX, SMT, and OTC [5]. Each treated plate was incubated at $30^{\circ} \mathrm{C}$ for $48 \mathrm{~h}$, followed by incubation for 1 week in the dark at room temperature. Colony forming units (CFUs) were enumerated at the end of the culture period [26].

2.4. DNA Extraction and Purification. DNA was extracted from $0.5 \mathrm{~g}$ of sediment or soil sample using a FastDNA SPIN kit (QBiogene, Carlsbad, CA, USA). The extracted DNA was purified using a Geneclean SPIN kit (QBiogene) to minimize PCR inhibition. The concentration of DNA before/after purification and recovery were determined.
2.5. Primer Design. Specific primers for nucleotide sequences encoding the TC- and SA-resistant genes were designed based on the GenBank Database (http://www.ncbi.nlm.nih.gov/). Seven sets of primers obtained from verifiable subjected products were generated as shown in Table 3.

2.6. Detection of ARGs Using Qualitative PCR. PCR was performed to identify the TC and SA ARGs encoding ribosomal protection. We used a Bio-Rad kit (Hercules, CA, USA) in a reaction mixture with a final volume of $20 \mu \mathrm{L}$ consisting each of $2 \mu \mathrm{L}$ of the $\times 10$ buffer, $2.5 \mathrm{mM}$ dNTP mix, $0.4 \mu \mathrm{M}$ each primer, 1.75 units of Taq DNA polymerase, and $50 \mathrm{pmol}$ of DNA template (Takara Bio, Shiga, Japan). Amplification was conducted using a PTC-100 thermal cycler (Bio-Rad) to subject samples to conditions of initial denaturation at $95^{\circ} \mathrm{C}$ for $5 \mathrm{~min}$, followed by 35 cycles of denaturation at $95^{\circ} \mathrm{C}$ for $30 \mathrm{~s}, 30 \mathrm{~s}$ annealing at $55.9^{\circ} \mathrm{C}$ for $\mathrm{SA}$ genes, $60^{\circ} \mathrm{C}$ for tet $(\mathrm{W}), 50.3^{\circ} \mathrm{C}$ for tet $(\mathrm{O}), 56^{\circ} \mathrm{C}$ for tet $(\mathrm{S}), 43.9^{\circ} \mathrm{C}$ for $\operatorname{tet} \mathrm{B}(\mathrm{P})$, or $43.9^{\circ} \mathrm{C}$ for tet $(\mathrm{T})$. Extension was done at $72^{\circ} \mathrm{C}$ for $30 \mathrm{~s}$ with a final extension at $72^{\circ} \mathrm{C}$ for $7 \mathrm{~min}$. The PCR products were visualized on a $0.8 \%$ agarose gel using a Gel Doc 1000 apparatus (Bio-Rad).

\section{Results and Discussion}

3.1. Antibiotic Concentrations. The concentrations of TCs and SAs in the sediment and soil samples are shown in Figure 1. TC was only detected in sediment \#1 $\left(0.39 \mu \mathrm{g} \mathrm{kg}^{-1}\right)$ (Figure 1(a)). TC and CTC antibiotic residues were detected in both soils \#1 and \#2, and the maximum concentrations of TC $\left(0.93 \mu \mathrm{g} \mathrm{kg}^{-1}\right)$ and CTC $\left(6.00 \mu \mathrm{g} \mathrm{kg}^{-1}\right)$ were observed in soil \#1. This result shows that the antibiotic residues in soils are more long-lasting than those in sediment because of lower mobility in soils. No OTC was found in any sample. For instance, stability of TCs is controlled by abiotic and biotic factors with a range of 1-419-day half-lives in 
TABLE 3: Polymerase chain-reaction (PCR) primers for tetracycline- (TC-) and sulfonamide- (SA-) resistant gene classes.

\begin{tabular}{|c|c|c|c|c|}
\hline Gene & Primer & Sequences & Annealing temp. $\left({ }^{\circ} \mathrm{C}\right)$ & Amplicon size (bp) \\
\hline \multirow{2}{*}{$\operatorname{tet}(\mathrm{S})$} & tetS-FW ${ }^{\dagger}$ & GAAAGCTTACTATACAGTAGC & \multirow{2}{*}{50} & \multirow{2}{*}{169} \\
\hline & tet $\mathrm{S}-\mathrm{RV}^{\ddagger}$ & AGGAGTATCTACAATATTTAC & & \\
\hline \multirow{2}{*}{$\operatorname{tet}(\mathrm{T})$} & tet T-FW & AAGGTTTATTATATAAAAGTG & \multirow{2}{*}{46} & \multirow{2}{*}{169} \\
\hline & tet $\mathrm{T}-\mathrm{RV}$ & AGGTGTATCTATGATATTTAC & & \\
\hline \multirow{2}{*}{$\operatorname{otr}(\mathrm{A})$} & otrA-FW & GGCATYCTGGCCCACGT & \multirow{2}{*}{66} & \multirow{2}{*}{212} \\
\hline & otrA-RV & CCCGGGGTGTCGTASAGG & & \\
\hline \multirow{2}{*}{$\operatorname{sul}(\mathrm{I})$} & sulI-FW & CGCACCGGAAACATCGCTGCAC & \multirow{2}{*}{55.9} & \multirow{2}{*}{163} \\
\hline & sulI-RV & TGAAGTTCCGCCGCAAGGCTCG & & \\
\hline \multirow{2}{*}{$\operatorname{sul}(\mathrm{II})$} & sulII-FW & TCCGGTGGAGGCCGGTATCTGG & \multirow{2}{*}{60.8} & \multirow{2}{*}{191} \\
\hline & sulII-RV & CGGGAATGCCATCTGCCTTGAG & & \\
\hline \multirow{2}{*}{$\operatorname{sul}(\mathrm{III})$} & sulIII-FW & TCCGTTCAGCGAATTGGTGCAG & \multirow{2}{*}{60} & \multirow{2}{*}{128} \\
\hline & sulIII-RV & TTCGTTCACGCCTTACACCAGC & & \\
\hline \multirow{2}{*}{$\operatorname{sul}(\mathrm{A})$} & sulA-FW & TCTTGAGCAAGCACTCCAGCAG & \multirow{2}{*}{60} & \multirow{2}{*}{229} \\
\hline & sulA-RV & TCCAGCCTTAGCAACCACATGG & & \\
\hline
\end{tabular}

${ }^{\dagger}$ Forward.

${ }^{\ddagger}$ Reverse.

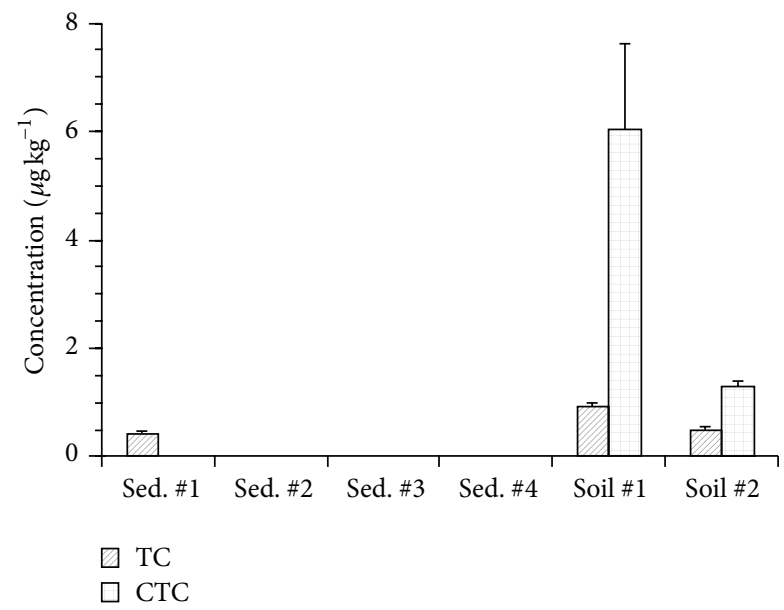

(a)

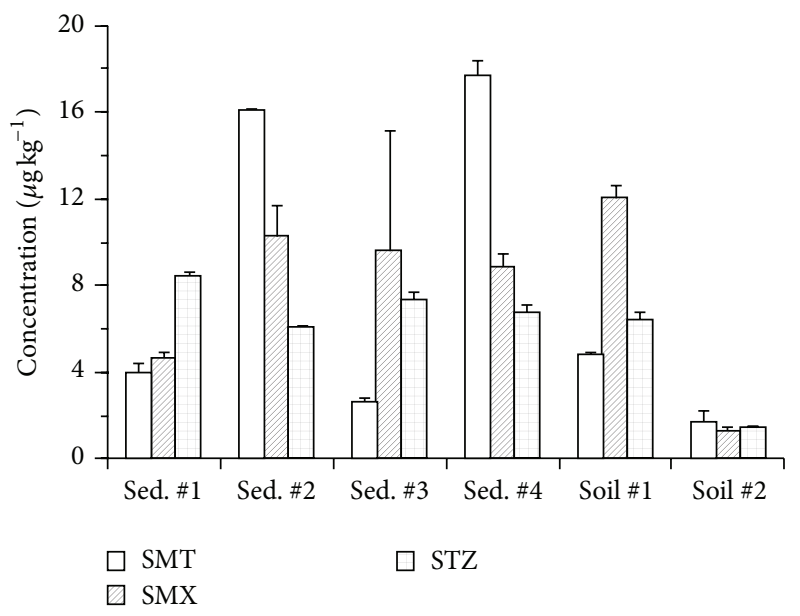

(b)

FIGURE 1: Average concentration of (a) tetracyclines (TCs) and (b) sulfonamides (SAs) in sediment and soil samples collected along the Naerincheon River downstream of a swine manure compositing facility.

aquatic systems [27]. In current study, TCs were below the detection limit in sediment samples and this might be due to their strong sorption affinity to aluminum oxide, Fe oxides, organic carbon, and clay particles in soil $[20,27,28]$. In particular, $\mathrm{Al}_{2} \mathrm{O}_{3}$ and $\mathrm{Fe}_{2} \mathrm{O}_{3}$ promote the dehydration of TC to anhydrotetracycline (AHTC), epimerization of TC, and formation of Al-TC and Fe-TC complexes [29-31]. In addition, Rubert [27] revealed that organic matter (humic and proteinaceous substances) can absorb TCs in soil and can form complexation of TC in the presence of cations such as $\mathrm{Ca}, \mathrm{Cu}, \mathrm{Al}$, and $\mathrm{Fe}$. Additionally, sorption of TCs was pronounced in rice paddy soils due to high cation exchange capacity by 9.24 and $8.90 \mathrm{cmol}_{(+)} \mathrm{kg}^{-1}$, respectively, for both soils as mentioned in our previous findings [20,31-33].

The maximum concentrations of SMT $\left(17.68 \mu \mathrm{g} \mathrm{kg}^{-1}\right)$ in sediment \#4, SMX $\left(10.24 \mu \mathrm{g} \mathrm{kg}^{-1}\right)$ in sediment \#2, and
STZ $\left(8.34 \mu \mathrm{g} \mathrm{kg}^{-1}\right)$ in sediment \#1 were found (Figure 1(b)). Similar to the TCs, a higher concentration of SAs was observed in soil \#1 than those in soil \#2. Additionally, the direct application of swine manure onto paddy soils (i.e., soil \#1) contributed to the longevity of antibiotic residues in soils compared to that of indirect application via irrigation water possibly contaminated with antibiotics (i.e., soil \#2).

These findings were in accordance with our previous study $[20,22]$ that the concentrations of TCs, including CTC, TC, and OTC, in sediment samples collected along the Naerincheon River are very low or below the detection limit. We showed earlier that the antibiotic residues of SAs, including SMT, SMX, and STZ, are highly detectable in sediment, indicating concentration levels of 38.60-70.32, 8.9112.20, and 23.68-40.31 $\mu \mathrm{g} \mathrm{kg}^{-1}$, respectively [20]. Our results for the trend of TCs and SAs concentrations in sediment and 
TABLE 4: Antibiotic-resistant bacteria in CFUs isolated from sediment and soil samples cultured on R2A agar plates with/without antibiotics after a $24 \mathrm{~h}$ incubation at $30^{\circ} \mathrm{C}$.

\begin{tabular}{|c|c|c|c|c|c|c|}
\hline & \multicolumn{6}{|c|}{ Plate counts of antibiotic-resistant bacteria (in $\mathrm{CFU} \times 10^{2}$ ) } \\
\hline & Sed. \#1 & Sed. \#2 & Sed. \#3 & Sed. \#4 & Soil \#1 & Soil \#2 \\
\hline Control & $217.00^{\mathrm{d} \dagger}$ & $241.00^{\mathrm{c}}$ & $193.00^{\mathrm{e}}$ & $179.00^{\mathrm{f}}$ & $298.00^{\mathrm{b}}$ & $316.00^{\mathrm{a}}$ \\
\hline Tetracycline (TC) & $\mathrm{ND}^{\ddagger}$ & $2.00^{\mathrm{a}}$ & ND & $0.33^{\mathrm{b}}$ & ND & ND \\
\hline Chlortetracycline (CTC) & ND & $0.67^{\mathrm{a}}$ & ND & ND & $1.00^{\mathrm{a}}$ & ND \\
\hline Sulfamethazine (SMT) & $145.33^{\mathrm{a}}$ & $126.67^{\mathrm{ab}}$ & $99.33^{\mathrm{b}}$ & $50.33^{\mathrm{c}}$ & $36.33^{c}$ & $33.33^{\mathrm{c}}$ \\
\hline Sulfamethoxazole (SMX) & $52.33^{\mathrm{b}}$ & $88.33^{\mathrm{a}}$ & $39.00^{\mathrm{cd}}$ & $14.33^{\mathrm{cd}}$ & $10.33^{\mathrm{d}}$ & $19.33^{\mathrm{cd}}$ \\
\hline Sulfathiazole (STZ) & $99.33^{\mathrm{a}}$ & $79.33^{\mathrm{a}}$ & $13.67^{\mathrm{b}}$ & $8.67^{\mathrm{b}}$ & $22.33^{\mathrm{b}}$ & $12.33^{\mathrm{b}}$ \\
\hline
\end{tabular}

${ }^{\dagger}$ Different letters in each row indicate a significant difference at 0.05 .

${ }^{\ddagger}$ Not detected.

TABLE 5: Polymerase chain-reaction (PCR) identification of antibiotic-resistant strains using different tetracycline (TC) and sulfonamide (SA) primers.

\begin{tabular}{lcccccc}
\hline Primer & Sed. \#1 & Sed. \#2 & Sed. \#3 & Sed. \#4 & Soil \#1 & Soil \#2 \\
\hline $\operatorname{tet}(\mathrm{S})$ & $-^{\dagger}$ & $\mathrm{O}^{\ddagger}$ & - & 0 & - & - \\
$\operatorname{tet}(\mathrm{T})$ & - & 0 & - & - & 0 & - \\
$\operatorname{str}(\mathrm{A})$ & - & - & - & 0 & 0 & - \\
$\operatorname{sul}(\mathrm{I})$ & - & 0 & 0 & 0 & 0 & 0 \\
$\operatorname{sul}(\mathrm{II})$ & 0 & 0 & 0 & 0 & 0 & 0 \\
$\operatorname{sul}(\mathrm{III})$ & 0 & 0 & 0 & 0 & 0 & 0 \\
$\operatorname{sul}(\mathrm{A})$ & 0 & 0 & 0 & 0 & 0 & 0 \\
\hline
\end{tabular}

${ }^{\dagger}$ Absent.

${ }^{\ddagger}$ Present.

soil samples were quite similar to our previous study [20], but the concentrations were much lower than their study. This discrepancy may be explained by seasonal variations in precipitation or temperature based on sampling season [24]. The potential effects of rainfall during winter season and highflow rate cause the dilution effect of the released veterinary antibiotics from CAFOs. Ok et al. [20] and Kim and Carlson [24] found that the concentration levels of antibiotic residues in water are strongly influenced by precipitation, water level, flow conditions, and water quality related to geographic conditions and type of antibiotic. It was noteworthy that the fourth highest temperature record since 1973 was observed in March with $1.5^{\circ} \mathrm{C}$ higher than normal mean temperature, while the annual precipitation in Hongcheon was $1000.4 \mathrm{~mm}$, based on weather information from the Korea Meteorological Administration [21, 34]. This also can be contributed to the degradation of TCs in solid matrices (animal manure and soil). Under soil acidic condition, OTC was epimerized in swine manure and formed degradation products such as 4epi-OT and epi-N-desmethyl-OT [27, 35]. Ingerslev et al. [36] found that biodegradation of TCs was the main mechanism in sludge by Ascomycetes fungi [37] and Streptomyces species; however, sorption and transformation of TCs commonly occurred in soil $[27,32]$. Our study confirmed that the transformation and stability of TCs in sediment and soil are dependent on light, temperature, and physiochemical properties of the matrix [38].

The reason for the higher concentrations or mobility of SAs compared to TCs is that SAs are likely moving a further distance from the composting facility because of lower organic carbon-normalized sorption coefficient $\left(K_{\mathrm{oc}}\right)$ and the lower hydrophobicity $[24,31]$. Hu et al. [39] also showed that SAs have a range of distribution coefficients $\left(K_{d}\right)$ of $0.9-18.1 \mathrm{~mL} \mathrm{~g}^{-1}$, indicating high solubility in water compared to other types of antibiotics.

3.2. Antibiotic-Resistant Bacteria. Total bacterial counts indicating antibiotic resistance (CFUs $\left.\times 10^{2}\right)$ are shown in Table 4 . Total bacterial counts in the sediment samples decreased with increasing distance from the swine composting facility as a release source of antibiotics. This result indicates that the antibiotic-resistant bacteria were present close to the antibiotic contamination source. The total enumeration of CFUs was much higher without antibiotics than with antibiotics, ranging from 179 to $241 \mathrm{CFU} \times 10^{2} \mathrm{~g}^{-1}$ for sediments and 298 to $316 \mathrm{CFU} \times 10^{2} \mathrm{~g}^{-1}$ for soils. The total bacterial count for SAs was 8.67-145.33 CFU $\times 10^{2} \mathrm{~g}^{-1}$ for sediments and 10.33-36.33 $\mathrm{CFU} \times 10^{2} \mathrm{~g}^{-1}$ for soils. These results indicate that the density of culturable heterotrophic bacteria was generally higher in sediment than that in soil. However, no bacteria were detected in any samples grown in the presence of TCs except in sediments $\# 2$ and \#4, indicating a very low population. This result agrees with a study by Pepper and Gerba [26] showing that SA-resistant bacteria are present in greater abundance than TC-resistant bacteria.

3.3. PCR Assay for ARGs. The occurrence of ARGs for TCs and SAs is shown in Table 5 and Figure 2. The results showed that SA-resistant genes including sul(I), sul(II), and 


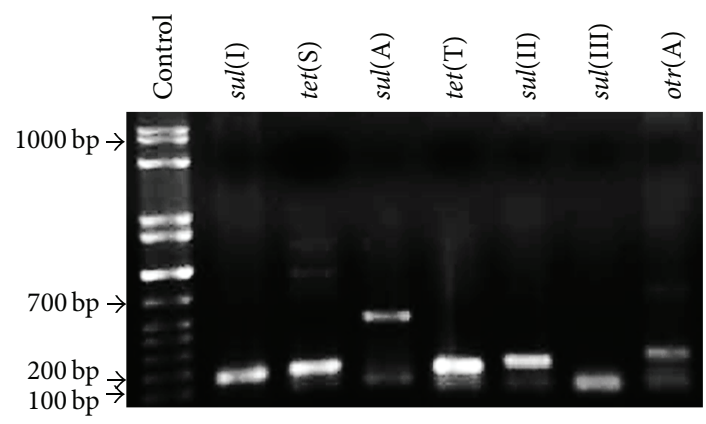

FIGURE 2: Polymerase chain-reaction (PCR) identification of antibiotic-resistant strains present in the sediment and soil samples.

sul(A) were present in all sediment and soil samples except sul(I), which was not detected in sediment \#1. However, TCresistant genes including tet $(\mathrm{S})$, tet $(\mathrm{T})$, and $\operatorname{otr}(\mathrm{A})$ were only found in sediments \#2 and \#4 and soil \#1. These findings agree with the study by Pei et al. [5] who quantified four SAand five TC-resistant genes in sediments collected along the Cache La Poudre River using both culture-based and PCR techniques. Auerbach et al. [11] also reported a wide variety of TC-resistant genes in different wastewater samples collected in the USA.

It was noteworthy that wastewater from CAFOs and the application of compost or animal manure to rice paddy soils play a significant role in generating ARGs for SAs in both sediments and soils due to the accumulation of veterinary antibiotics. Similarly, ARGs for TCs were found in rice paddy soils. Similar to our results, previous studies reported that ARGs were generated at higher levels near CAFOs than background and associated with human and animal diseases, including different pathogenic bacteria such as Salmonella and Shigella isolates [40]. For example, they found a significant correlation between the occurrence of methicillin-resistant Staphylococcus aureus (MRSA) in pigs and pig farmers in USA, Canada, and Europe [40, 41]. Thus, the findings of current study agree with previous studies $[4,5,8,11,40,41]$ and demonstrate that antibiotic use in CAFOs is highly correlated with the fate and transport of ARGs in surrounding environment. In a survey by Peak et al. [42], a strong correlation between antibiotics and ARGs was identified.

\section{Conclusions}

This study was conducted to investigate the residual concentrations of selected TCs and SAs and to isolate corresponding ARGs in the environment. Higher concentrations of SAs in sediment and soil samples were found compared to those of TCs. A culture-based technique and PCR were successfully used to demonstrate TC- and SA-resistant genes in the environment. Findings of current study revealed that the widespread antibiotic use in CAFOs in Korea has the potential to generate ARGs as emerging contaminants in solid environmental matrices. Monitoring ARGs in surrounding environments is encouraged to ensure public health. Freeantibiotic swine industry in Korea is recommended to reduce the environmental risks of veterinary antibiotics.

\section{Conflict of Interests}

The authors declare that there is no conflict of interests regarding the publication of this paper.

\section{Acknowledgments}

The authors thank Dr. Ruoting Pei at the University of Texas at San Antonio for a valuable review. This research was supported by the Ministry of Environment as "The GAIA Project (no. 172-112-011)" in Korea. Instrumental analysis was supported by a grant from the Institute of Environmental Research and the Central Laboratory at Kangwon National University in Korea.

\section{References}

[1] S. B. Levy, "The challenge of antibiotic resistance," Scientific American, vol. 278, no. 3, pp. 46-53, 1998.

[2] K.-R. Kim, G. Owens, S.-I. Kwon, K.-H. So, D.-B. Lee, and Y. S. Ok, "Occurrence and environmental fate of veterinary antibiotics in the terrestrial environment," Water, Air, \& Soil Pollution, vol. 214, no. 1-4, pp. 163-174, 2011.

[3] F. C. Cabello, "Heavy use of prophylactic antibiotics in aquaculture: a growing problem for human and animal health and for the environment," Environmental Microbiology, vol. 8, no. 7, pp. 1137-1144, 2006.

[4] K. Kümmerer and A. Henninger, "Promoting resistance by the emission of antibiotics from hospitals and households into effluent," Clinical Microbiology and Infection, vol. 9, no. 12, pp. 1203-1214, 2003.

[5] R. Pei, S.-C. Kim, K. H. Carlson, and A. Pruden, "Effect of river landscape on the sediment concentrations of antibiotics and corresponding antibiotic resistance genes (ARG)," Water Research, vol. 40, no. 12, pp. 2427-2435, 2006.

[6] S. I. Kwon, G. Owens, Y. S. Ok et al., "Applicability of the Charm II system for monitoring antibiotic residues in manure-based composts," Waste Management, vol. 31, no. 1, pp. 39-44, 2011.

[7] S. C. Kim, Occurrence, fate and transport of human and veterinary antibiotics in the watershed [Ph.D. dissertation], Colorado State University, Fort Collins, Colo, USA, 2006.

[8] J. C. Chee-Sanford, R. I. Aminov, I. J. Krapac, N. GarriguesJeanjean, and R. I. Mackie, "Occurrence and diversity of tetracycline resistance genes in lagoons and groundwater underlying two swine production facilities," Applied and Environmental Microbiology, vol. 67, no. 4, pp. 1494-1502, 2001.

[9] O. Cars, L. D. Högberg, M. Murray, O. Nordberg, C. S. Lundborg, and A. D. So, "Meeting the challenge of a concerted global response is needed to tackle rising rates of antibiotic resistance. Without it, we risk returning to the pre-antibiotic era warn," British Medical Journal, vol. 337, pp. 726-728, 2008.

[10] Y. M. Awad, S. S. Lee, S. C. Kim, J. E. Yang, and Y. S. Ok, "Novel approaches to monitoring and remediation of veterinary antibiotics in soil and water: a review," Korea Journal of Environmental Agriculture, vol. 29, no. 4, pp. 315-327, 2010. 
[11] E. A. Auerbach, E. E. Seyfried, and K. D. McMahon, "Tetracycline resistance genes in activated sludge wastewater treatment plants," Water Research, vol. 41, no. 5, pp. 1143-1151, 2007.

[12] G. Sengeløv, Y. Agersø, B. Halling-Sørensen, S. B. Baloda, J. S. Andersen, and L. B. Jensen, "Bacterial antibiotic resistance levels in Danish farmland as a result of treatment with pig manure slurry," Environment International, vol. 28, no. 7, pp. 587-595, 2003.

[13] M. Rysz and P. J. J. Alvarez, "Amplification and attenuation of tetracycline resistance in soil bacteria: aquifer column experiments," Water Research, vol. 38, no. 17, pp. 3705-3712, 2004.

[14] D. Schnappinger and W. Hillen, "Tetracyclines: antibiotic action, uptake, and resistance mechanisms," Archives of Microbiology, vol. 165, no. 6, pp. 359-369, 1996.

[15] B. Normander, B. B. Christensen, S. Molin, and N. Kroer, "Effect of bacterial distribution and activity on conjugal gene transfer on the phylloplane of the bush bean (Phaseolus vulgaris)," Applied and Environmental Microbiology, vol. 64, no. 5, pp. 1902-1909, 1998.

[16] R. I. Amann, W. Ludwig, and K.-H. Schleifer, "Phylogenetic identification and in situ detection of individual microbial cells without cultivation," Microbiological Reviews, vol. 59, no. 1, pp. 143-169, 1995.

[17] C. S. Riesenfeld, R. M. Goodman, and J. Handelsman, "Uncultured soil bacteria are a reservoir of new antibiotic resistance genes," Environmental Microbiology, vol. 6, no. 9, pp. 981-989, 2004.

[18] C. W. Knapp, J. Dolfing, P. A. I. Ehlert, and D. W. Graham, "Evidence of increasing antibiotic resistance gene abundances in archived soils since 1940," Environmental Science and Technology, vol. 44, no. 2, pp. 580-587, 2010.

[19] V. Burdett, "Purification and characterization of Tet(M), a protein that renders ribosomes resistant to tetracycline," The Journal of Biological Chemistry, vol. 266, no. 5, pp. 2872-2877, 1991.

[20] Y. S. Ok, S.-C. Kim, K.-R. Kim et al., "Monitoring of selected veterinary antibiotics in environmental compartments near a composting facility in Gangwon Province, Korea," Environmental Monitoring and Assessment, vol. 174, no. 1-4, pp. 693-701, 2011.

[21] KMA, "Korea Meteorological Administration," 2015, http://web .kma.go.kr/eng/index.jsp.

[22] Y. M. Awad, S.-C. Kim, S. A. M. Abd El-Azeem et al., "Veterinary antibiotics contamination in water, sediment, and soil near a swine manure composting facility," Environmental Earth Sciences, vol. 71, no. 3, pp. 1433-1440, 2014.

[23] KMA, Monthly Weather Report, Pub\# 11-1360000-00000206, Korea Meteorological Administration, Seoul, Republic of Korea, 2009.

[24] S.-C. Kim and K. Carlson, "Temporal and spatial trends in the occurrence of human and veterinary antibiotics in aqueous and river sediment matrices," Environmental Science and Technology, vol. 41, no. 1, pp. 50-57, 2007.

[25] S.-C. Kim and K. Carlson, "LC-MS ${ }^{2}$ for quantifying trace amounts of pharmaceutical compounds in soil and sediment matrices," Trends in Analytical Chemistry, vol. 24, no. 7, pp. 635644, 2005.

[26] I. L. Pepper and C. P. Gerba, "Cultural methods," in Environmental Microbiology, R. M. Maier, I. L. Pepper, and P. C. Gerba, Eds., pp. 173-188, Academic Press Elsevier Inc., London, UK, 2nd edition, 2009.
[27] K. F. Rubert, Tetracycline Antibiotic Distribution and Transformation in Aquatic Systems, ProQuest, 2008.

[28] W.-R. Chen and C.-H. Huang, "Adsorption and transformation of tetracycline antibiotics with aluminum oxide," Chemosphere, vol. 79, no. 8, pp. 779-785, 2010.

[29] R. A. Figueroa and A. A. Mackay, "Sorption of oxytetracycline to iron oxides and iron oxide-rich soils," Environmental Science and Technology, vol. 39, no. 17, pp. 6664-6671, 2005.

[30] C. Gu and K. G. Karthikeyan, "Interaction of tetracycline with aluminum and iron hydrous oxides," Environmental Science and Technology, vol. 39, no. 8, pp. 2660-2667, 2005.

[31] J. Tolls, "Sorption of veterinary pharmaceuticals in soils: a review, Environmental Science and Technology, vol. 35, no. 17, pp. 3397-3406, 2001.

[32] S. A. Sassman and L. S. Lee, "Sorption of three tetracyclines by several soils: assessing the role of $\mathrm{pH}$ and cation exchange," Environmental Science and Technology, vol. 39, no. 19, pp. 74527459, 2005.

[33] A. D. Jones, G. L. Bruland, S. G. Agrawal, and D. Vasudevan, "Factors influencing the sorption of oxytetracycline to soils," Environmental Toxicology and Chemistry, vol. 24, no. 4, pp. 761770, 2005.

[34] J.-C. Yang, H.-S. Hwang, H.-J. Lee et al., "Distribution of vascular plants along the altitudinal gradient of Gyebangsan (Mt.) in Korea," Journal of Asia-Pacific Biodiversity, vol. 7, no. 1, pp. e40-e71, 2014.

[35] B. Halling-Sørensen, A. Lykkeberg, F. Ingerslev, P. Blackwell, and J. Tjørnelund, "Characterisation of the abiotic degradation pathways of oxytetracyclines in soil interstitial water using LCMS-MS," Chemosphere, vol. 50, no. 10, pp. 1331-1342, 2003.

[36] F. Ingerslev, L. Toräng, M.-L. Loke, B. Halling-Sorensen, and N. Nyholm, "Primary biodegradation of veterinary antibiotics in aerobic and anaerobic surface water simulation systems," Chemosphere, vol. 44, no. 4, pp. 865-872, 2001.

[37] E. Meyers and D. A. Smith, "Microbiological degradation of tetracyclines," Journal of Bacteriology, vol. 84, no. 4, pp. 797-802, 1962.

[38] T. Søeborg, F. Ingerslev, and B. Halling-Sørensen, "Chemical stability of chlortetracycline and chlortetracycline degradation products and epimers in soil interstitial water," Chemosphere, vol. 57, no. 10, pp. 1515-1524, 2004.

[39] X. Hu, Q. Zhou, and Y. Luo, “Occurrence and source analysis of typical veterinary antibiotics in manure, soil, vegetables and groundwater from organic vegetable bases, northern China," Environmental Pollution, vol. 158, no. 9, pp. 2992-2998, 2010.

[40] A. Pruden, "Antibiotic resistance associated with CAFOs," in Hormones and Pharmaceuticals Generated by Concentrated Animal Feeding Operations: Transport in Water and Soil, L. S. Shore and A. Pruden, Eds., vol. 1 of Emerging Topics in Ecotoxicology, pp. 71-83, Springer, New York, NY, USA, 2009.

[41] T. Khanna, R. Friendship, C. Dewey, and J. S. Weese, "Methicillin resistant Staphylococcus aureus colonization in pigs and pig farmers," Veterinary Microbiology, vol. 128, no. 3-4, pp. 298 303, 2008.

[42] N. Peak, C. W. Knapp, R. K. Yang et al., "Abundance of six tetracycline resistance genes in wastewater lagoons at cattle feedlots with different antibiotic use strategies," Environmental Microbiology, vol. 9, no. 1, pp. 143-151, 2007. 

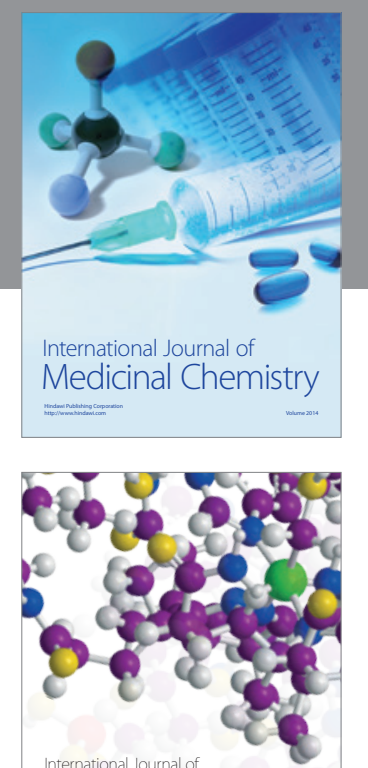

\section{Carbohydrate} Chemistry

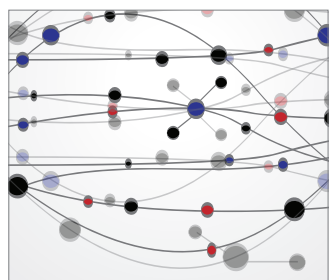

The Scientific World Journal
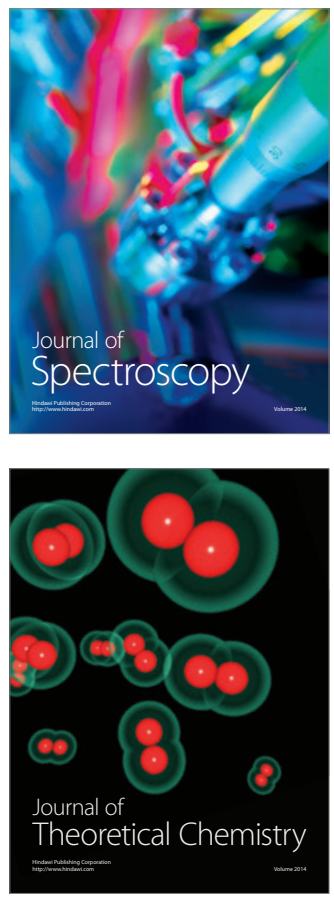
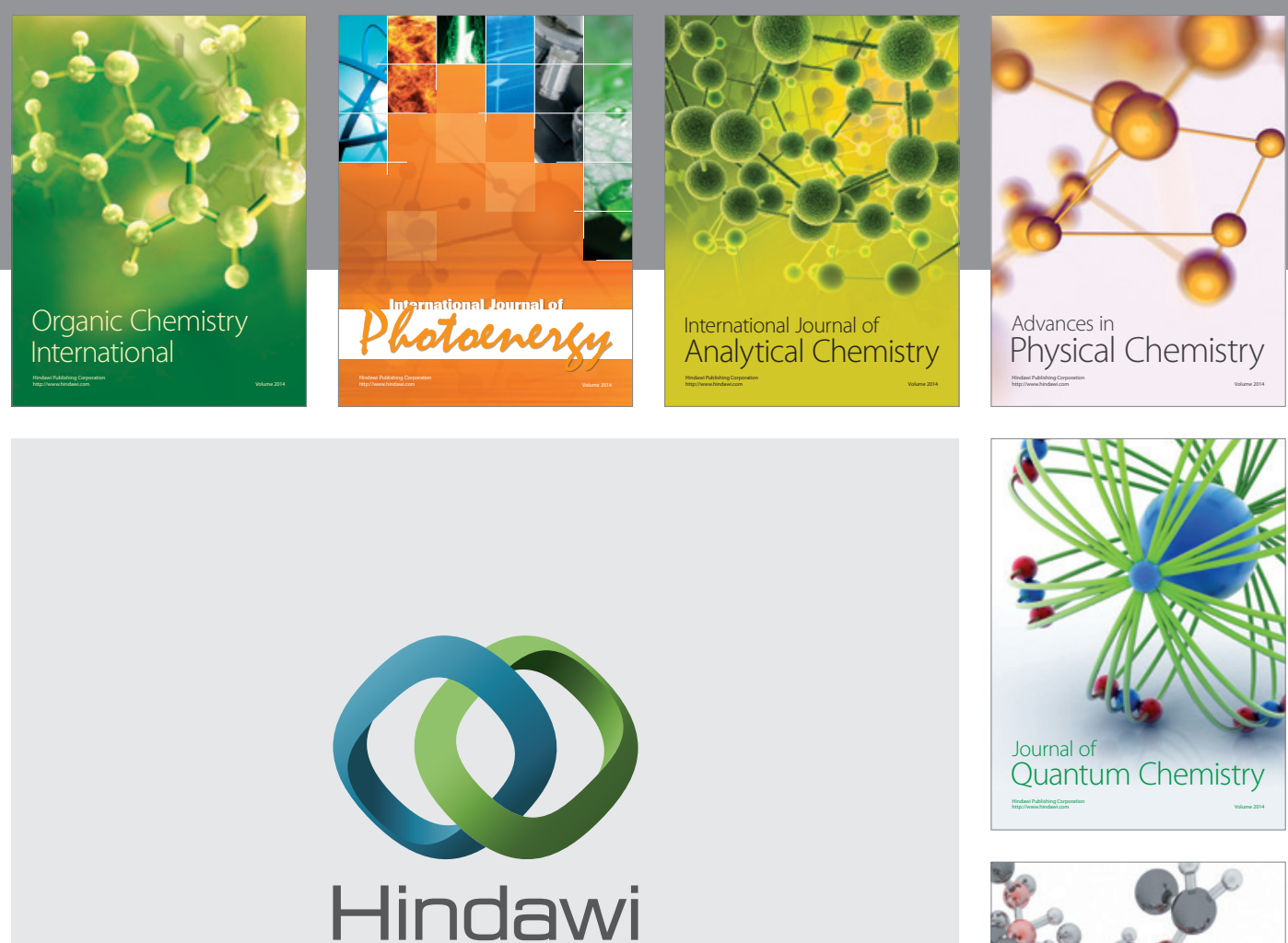

Submit your manuscripts at

http://www.hindawi.com

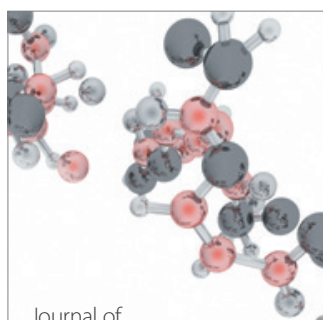

Analytical Methods

in Chemistry

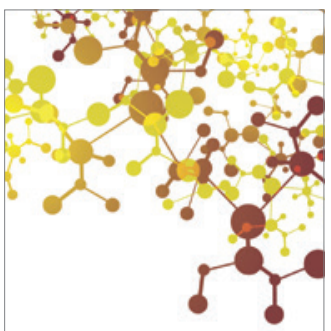

Journal of

Applied Chemistry

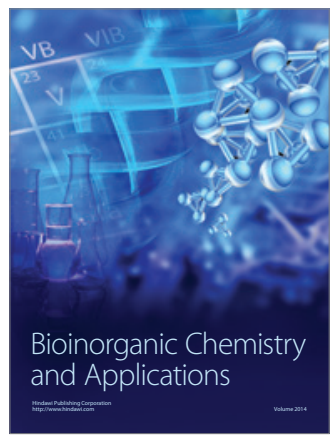

Inorganic Chemistry
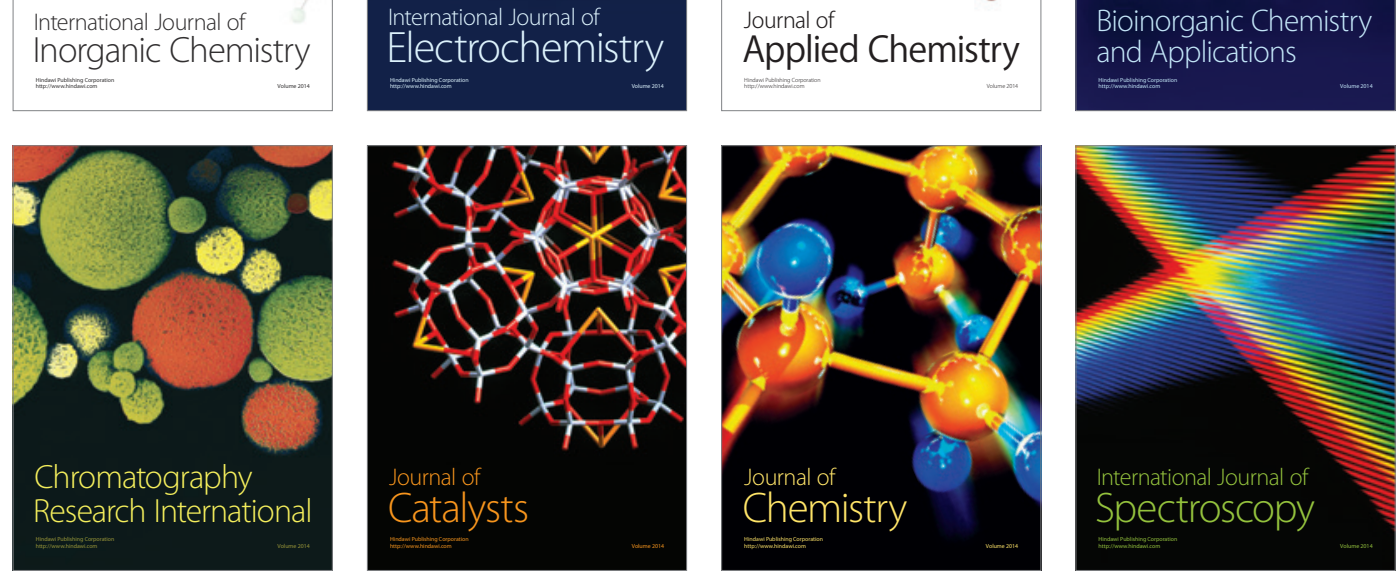